EPiC Series in Engineering
Volume 3, 2018, Pages 2187-2195
HIC 2018. 13th International
Conference on Hydroinformatics

\title{
Experimental and numerical analysis of the hydraulic performance of filtering cartridges for water treatment
}

\author{
Giacomo Viccione $^{1^{*}}$ and Stefania Evangelista ${ }^{2}$ \\ ${ }^{1}$ Università degli Studi di Salerno, 84084 Fisciano (SA), Italy \\ ${ }^{2}$ Università di Cassino e del Lazio Meridionale, 03043 Cassino (FR), Italy \\ gviccion@unisa.it, s.evangelista@unicas.it
}

\begin{abstract}
Water treatments are progressively increasing their importance nowadays due to the gradual deterioration of water quality as a consequence of the environmental pollution and of industrial processes. Among these treatments, filtration still represents a major solution. In this work some results of a laboratory experimental analysis of the hydraulic performances of commercial cartridges for water treatment with filtration are presented in comparison with the results obtained by numerical simulations of the same physical model performed through the EPANET software. Specifically, the performance of filter cartridges is evaluated in terms of the head losses that they produce in the hydraulic systems in which they are introduced. These losses can be particularly undesirable for low-pressure plants, where they can inhibit the normal operation of the installed apparatus. Head losses also increase significantly with a prolonged use over time, due to the clogging particles retained on the outer surface and inside the cartridge, with a consequent reduction in the filtration capacity which generates the necessity to replace the cartridge itself. The comparison between numerical and experimental results showed a good agreement. The analysis of the data permitted to highlight several features of the filtration process in these commercial cartridges and draw up different remarks for their design and production.
\end{abstract}

\section{Introduction}

This work focuses on the analysis of the hydraulic performance, specifically in terms of head losses, of commercial string-wound filtering cartridges for water treatment, very commonly installed in most of domestic plants. These head losses can be significant, especially when the cartridge is installed in

${ }^{*}$ Corresponding author

G. La Loggia, G. Freni, V. Puleo and M. De Marchis (eds.), HIC 2018 (EPiC Series in Engineering, vol. 3), pp. $2187-2195$ 
water networks characterized by low hydraulic heads, when the resulting pressure levels can fall below the recommended minimum limit to ensure the proper functioning of water supplying domestic appliances. The literature analysis offers few studies on this topic, also not general and focused on specific features or on water quality aspects, such as the removal of specific substances from drinking water (Kanade \& Bhattacharya, 2016), (Logsdon, 2008), (Sutherland, 2008), (Kanade, Koranne, \& Desai, 2017), (Pawlowicz, Evans, Johnson, \& Brooks, 2006), (Tomaszewska, et al., 2016).

The present study was conducted first through an experimental campaign in a physical model built at the Environmental and Maritime Hydraulics Laboratory (LIDAM) of University of Salerno, Italy. Different experimental scenarios were simulated in a laboratory circuit including the cartridge, with different operating conditions; in each of them pressures were measured upstream and downstream of the cartridge, and thus the head losses produced at the flow transit through it were evaluated (Viccione \& Evangelista, 2017.a). In the experiments also a progressive artificial clogging of the filter was taken into account. With a prolonged use over time, in fact, head losses increase significantly due to the particles retained on the outer surface and inside the cartridge, which make the fluid have less flow space (Viccione \& Evangelista, 2017.b), (Viccione, Evangelista, \& de Marinis, 2018.a), (Viccione, Evangelista, \& de Marinis, 2018.b) The reduction in the filtration capacity generates the necessity to replace the cartridge.

Subsequently, numerical simulations of the same hydraulic processes were performed using the EPANET software. The numerical modelling allowed a greater number of scenarios to be simulated comparing to the laboratory physical ones, thus providing a greater amount of data. The comparison of the numerical results against the experimental data, in fact, showed a good agreement, thus proving a satisfactory reliability of the numerical model. The overall analysis has permitted to better understand the filtration process through the cartridge and to draw up some useful suggestions for their design and production.

\section{Laboratory setup and experiments}

The hydraulic circuit was designed and built at the aim of simulating in a laboratory a generic civilian user with a cartridge filtration system, in order to calculate the local head losses produced by the cartridge itself (Figure 1).

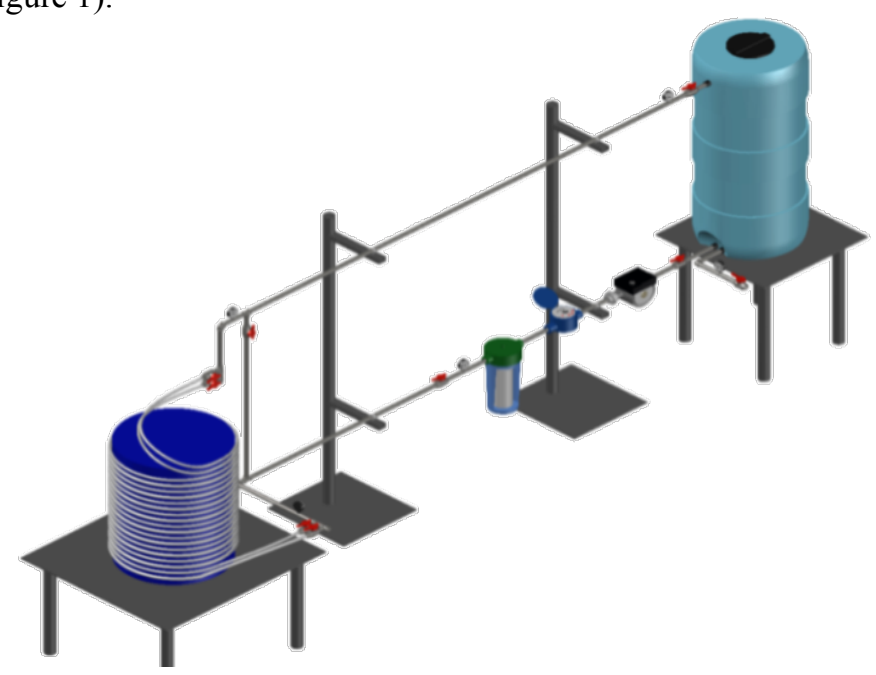

Figure 1: Sketch of the laboratory hydraulic circuit 
It consists essentially of: a polyethylene tank with capacity of 3001 , an electronic pump (maximum head $6.9 \mathrm{~m}$, flow rate $0.4 \div 3.3 \mathrm{~m}^{3} / \mathrm{h}$ ), a galvanized steel pipe with diameter $\phi^{3} / 4$ ", two multi-layer pipes linked in parallel with diameter $\phi 16$ and $\phi 20$, respectively, a single-jet water meter, a housing element with interchangeable filter cartridges.

The pipe connections with valves allows a flexibility of the system and the possibility to simulate typical domestic water networks in different operating conditions. In each case experiments have been performed with three different values of discharge $\left(\mathrm{Q}_{\min }, \mathrm{Q}_{\text {int }}\right.$-intermediate- and $\left.\mathrm{Q}_{\max }\right)$, depending on the operating modes of the pump, first with no filter cartridges and then inserting the filter cartridge (Figure 2) in the proper plastic container (by Acqua Brevetti 95 S.r.l., Mestrino, PD, Italy). The pressure drop over the filter is measured by a differential pressure gauge (model Digitron Engineering B.V. 2082P). Each measurement has been performed three times in order to verify the repeatability of the experimental tests.
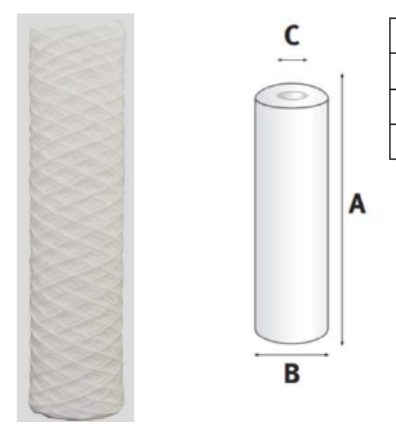

\begin{tabular}{|c|c|}
\hline A & $250 \mathrm{~mm}$ \\
\hline B & $61 \mathrm{~mm}$ \\
\hline C & $28 \mathrm{~mm}$ \\
\hline weight & $149 \mathrm{~g}$ \\
\hline
\end{tabular}

A

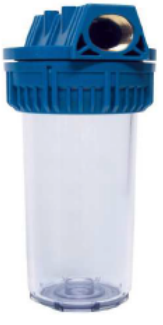

Figure 2: Wire-wound filter cartridge with dimensional information and plastic holder

The performance of the cartridge in the clogging conditions has been tested with the only galvanized steel pipe, since the focus is on the head loss produced by the filter cartridge, and it is possible to neglect the consideration of the rest of the hydraulic circuit, isolated by the closing of the proper valves. The artificial obstruction of the cartridge was obtained by laying sand over the filter surface in modular amounts (10 $\mathrm{g}$ at a time), up to an acceptable total amount $(80 \mathrm{~g})$ so to record appreciable variations in head losses at each increment.

\section{Numerical model and simulations}

The physical hydraulic circuit has been also reproduced in EPANET framework in order to perform hydraulic simulations for the numerical evaluations of the same head losses in the filtering cartridge. EPANET (Rossman, Computer Models/EPANET, 1999), (Rossman, EPANET 2 Users Manual, EPA/600/R-00/057, 2000), developed by the United States Environmental Protection Agency (EPA), is a water distribution system modelling software package intended for the simulation of hydraulic and water-quality behavior within pressurized pipe networks. Spatially and temporally varying water demand, pumps described by their internal curves, minor head losses arising from bends and various types of valves e.g. pressure and flow control, shutoffs and so on can be easily implemented.

The reliability of the numerical model has been proved by comparison of the simulations results with the laboratory observed ones. Then more simulations were performed.

Figure 3 shows all the components of the circuit: two tanks, the pump, the valve, nine nodes and eight reaches connecting the components to each other. 


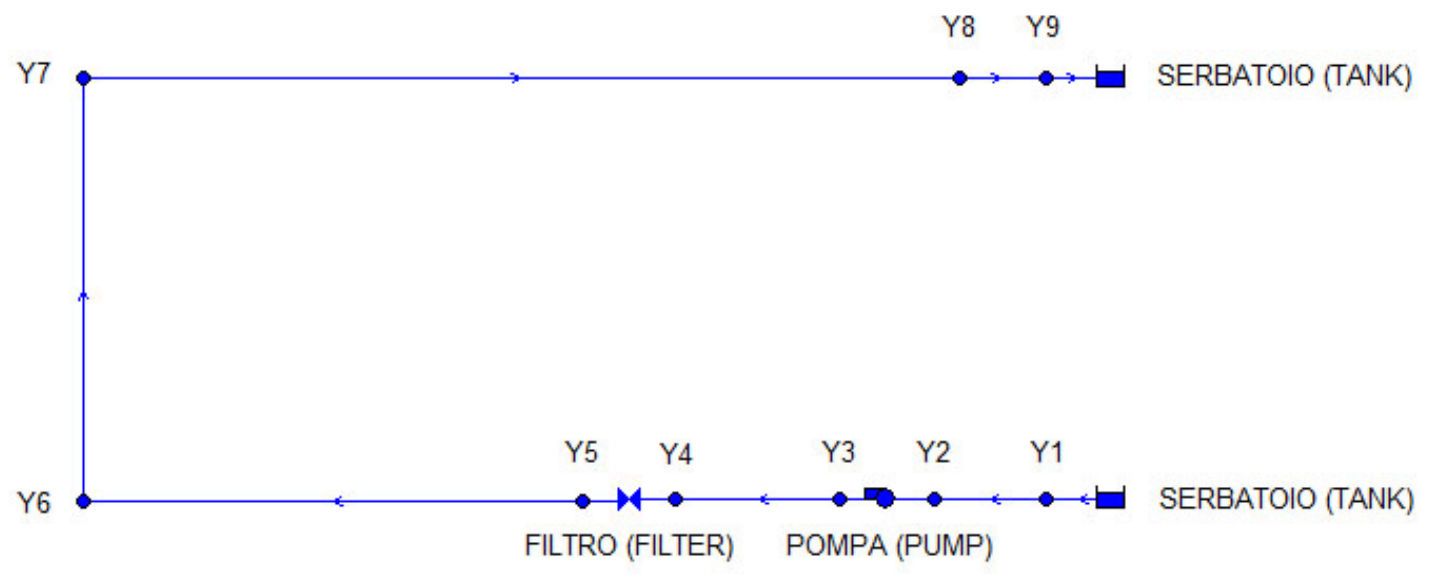

Figure 3: Scheme of the EPANET hydraulic model

Input data for the pressurized circuit were: the total head for the tanks, the geometrical features of the pipes (length, diameter and roughness), the geometric elevation of the junctions and the pump characteristic curve. The valve representing the filtering cartridge has been modelled as a Pressure Breaker Valve (PBV), a particular type of valve that permits to set the pressure drop due to the filter in the section in which it is inserted and the diameter of the valve itself.

\section{Results}

The results of this study are here reported directly as a comparison between numerical and experimental ones, in particular in terms of the nodes total heads $\Delta \mathrm{H}$ and of the piezometric slope or unit head loss $\mathrm{J}$ of the circuit. Nodes were numbered as sketched in Figure 4.

The roughness of the galvanized steel pipe was numerically calibrated by best fitting the experimental total heads, obtaining a Hazen-Williams coefficient $\mathrm{C}=117$.

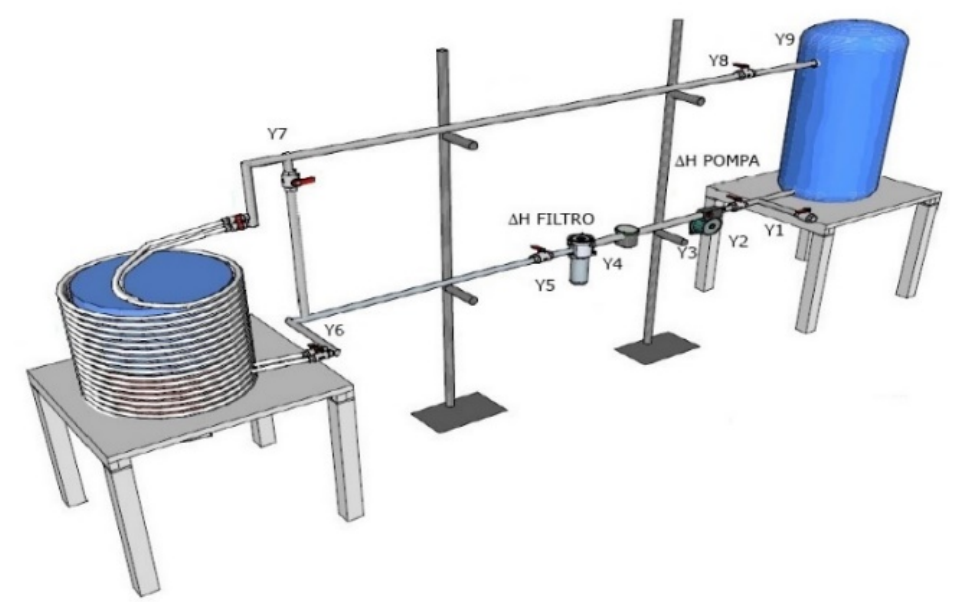

Figure 4: A schematic view of the circuit with specification of the nodes 
Experimental and Numerical Analysis of the Hydraulic Performance ...G. Viccione and S. Evangelista

Table 1 shows, respectively, the data obtained from the experimental measurements on the laboratory physical model and the results of the calculations performed by EPANET on the numerical hydraulic model, in the case of $20 \mathrm{~g}$ of sand added for the clogging process, i.e. of $16 \mathrm{~g}$ effective sand residual weight $\mathrm{w}_{\mathrm{r}, \mathrm{s}}$.

\begin{tabular}{lcccccc}
\hline & \multicolumn{2}{c}{ Minimum Velocity } & \multicolumn{2}{c}{ Intermediate Velocity } & \multicolumn{2}{c}{ Maximum Velocity } \\
\hline $\mathrm{Q}[\mathrm{l} / \mathrm{s}]$ & Experim. & Numerical. & Experim. & Numerical. & Experim. & Numerical. \\
$\Delta \mathrm{H}_{\text {pump }}[\mathrm{m}]$ & 0.27 & 0.27 & 0.35 & 0.35 & 0.40 & 0.40 \\
$\Delta \mathrm{H}_{\text {filter }}[\mathrm{m}]$ & 0.95 & 0.95 & 1.42 & 1.50 & 1.61 & 1.64 \\
$\mathrm{~J}[\mathrm{~m} / \mathrm{km}]$ & 0.27 & 0.27 & 0.40 & 0.40 & 0.52 & 0.52 \\
$\mathrm{Y}_{1}[\mathrm{~m}]$ & 70.91 & 68.35 & 122.12 & 124.37 & 154.46 & 143.43 \\
$\mathrm{Y}_{2}[\mathrm{~m}]$ & 1.50 & 1.50 & 1.50 & 1.50 & 1.50 & 1.50 \\
$\mathrm{Y}_{3}[\mathrm{~m}]$ & 1.48 & 1.48 & 1.47 & 1.46 & 1.46 & 1.46 \\
$\mathrm{Y}_{4}[\mathrm{~m}]$ & 2.43 & 2.43 & 2.88 & 2.86 & 3.07 & 3.09 \\
$\mathrm{Y}_{5}[\mathrm{~m}]$ & 2.37 & 2.37 & 2.79 & 2.77 & 2.95 & 2.98 \\
$\mathrm{Y}_{6}[\mathrm{~m}]$ & 2.10 & 2.10 & 2.39 & 2.37 & 2.43 & 2.46 \\
$\mathrm{Y}_{7}[\mathrm{~m}]$ & 2.01 & 2.01 & 2.24 & 2.22 & 2.24 & 2.28 \\
$\mathrm{Y}_{8}[\mathrm{~m}]$ & 1.98 & 1.98 & 2.11 & 2.08 & 2.20 & 2.13 \\
\hline $\mathrm{Table}$ & 1.84 & 1.84 & 1.86 & 1.83 & 1.88 & 1.83 \\
\hline
\end{tabular}

Table 1: Experimental vs numerical results in the case of $20 \mathrm{~g}(16 \mathrm{~g} \mathrm{wr}, \mathrm{s})$ of sand added for clogging

It can be observed the good correspondence between numerical results and experimental data: for example, in the minimum velocity condition in Table 1 is can be read the value of total head in node 3 , $\mathrm{Y}_{3}$, equal to $2.43 \mathrm{~m}$, and the piezometric slope of $70.91 \mathrm{~m} / \mathrm{km}$, whereas the EPANET results give a total head of $2.44 \mathrm{~m}$ for junction 4 and a unit head loss for the pipe with filter (pipe 4) of $68.84 \mathrm{~m} / \mathrm{km}$.

In Figure 5 the comparison is plotted to show better how the numerical and experimental results fit in a very satisfactory way, especially in terms of head losses produced by the filter, whose calculation is the main objective of this work, here plotted against the different values of discharges in the three different operating conditions of the system.

Tables 2-7 show, respectively, the same comparisons of experimental versus EPANET numerical results, in the cases of $30,40,50,60,70,80 \mathrm{~g}$ of sand added for the clogging process, respectively.

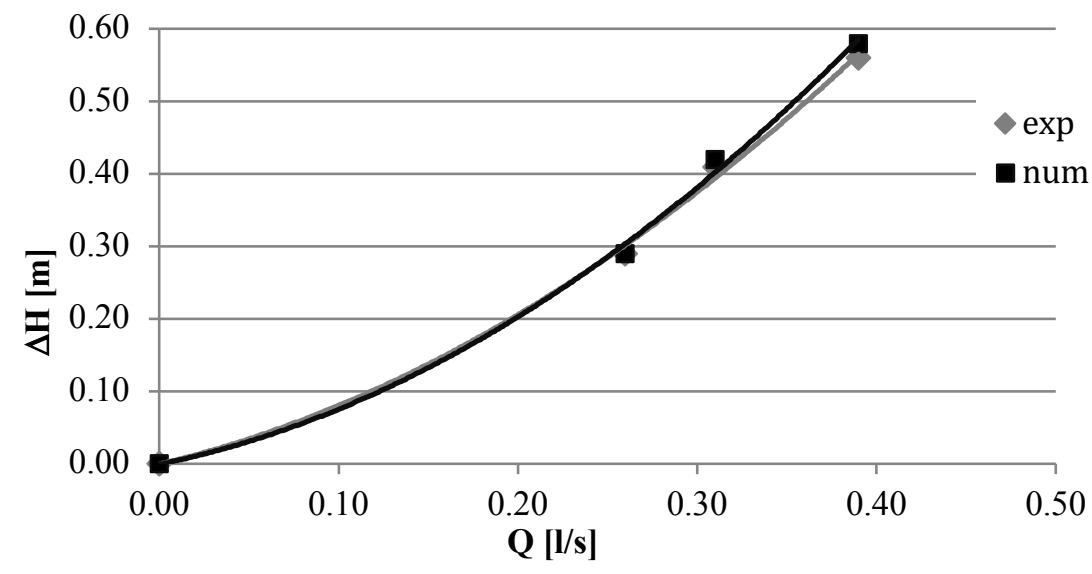

Figure 5: Numerical and experimental head losses at the filter in the case of $20 \mathrm{~g}(16 \mathrm{~g} \mathrm{wr}, \mathrm{s})$ of sand added for clogging 
Experimental and Numerical Analysis of the Hydraulic Performance ...G. Viccione and S. Evangelista

\begin{tabular}{lcccccc}
\hline & \multicolumn{2}{c}{ Minimum Velocity } & \multicolumn{2}{c}{ Intermediate Velocity } & \multicolumn{2}{c}{ Maximum Velocity } \\
\hline & Experim. & Numerical. & Experim. & Numerical. & Experim. & Numerical. \\
$\mathrm{Q}[\mathrm{l} / \mathrm{s}]$ & 0.26 & 0.26 & 0.31 & 0.31 & 0.39 & 0.39 \\
$\Delta \mathrm{H}_{\text {pump }}[\mathrm{m}]$ & 0.96 & 0.97 & 1.24 & 1.26 & 1.63 & 1.65 \\
$\Delta \mathrm{H}_{\text {filter }}[\mathrm{m}]$ & 0.29 & 0.29 & 0.41 & 0.42 & 0.56 & 0.58 \\
$\mathrm{~J}[\mathrm{~m} / \mathrm{km}]$ & 68.12 & 67.35 & 97.36 & 94.38 & 148.63 & 138.48 \\
$\mathrm{Y}_{1}[\mathrm{~m}]$ & 1.50 & 1.50 & 1.50 & 1.50 & 1.50 & 1.50 \\
$\mathrm{Y}_{2}[\mathrm{~m}]$ & 1.48 & 1.48 & 1.47 & 1.47 & 1.46 & 1.46 \\
$\mathrm{Y}_{3}[\mathrm{~m}]$ & 2.44 & 2.45 & 2.71 & 2.72 & 3.09 & 3.11 \\
$\mathrm{Y}_{4}[\mathrm{~m}]$ & 2.38 & 2.40 & 2.64 & 2.65 & 2.97 & 3.01 \\
$\mathrm{Y}_{5}[\mathrm{~m}]$ & 2.09 & 2.11 & 2.22 & 2.23 & 2.40 & 2.43 \\
$\mathrm{Y}_{6}[\mathrm{~m}]$ & 2.01 & 2.02 & 2.10 & 2.12 & 2.22 & 2.26 \\
$\mathrm{Y}_{7}[\mathrm{~m}]$ & 1.98 & 1.95 & 2.04 & 2.02 & 2.17 & 2.11 \\
$\mathrm{Y}_{8}[\mathrm{~m}]$ & 1.84 & 1.82 & 1.85 & 1.82 & 1.86 & 1.83 \\
\hline
\end{tabular}

Table 2: Experimental vs numerical results in the case of $30 \mathrm{~g}(20 \mathrm{~g} \mathrm{wr}, \mathrm{s})$ of sand added for clogging

\begin{tabular}{lcccccc}
\hline & \multicolumn{2}{c}{ Minimum Velocity } & \multicolumn{2}{c}{ Intermediate Velocity } & \multicolumn{2}{c}{ Maximum Velocity } \\
\hline & Experim. & Numerical. & Experim. & Numerical. & Experim. & Numerical. \\
$\mathrm{Q}[\mathrm{l} / \mathrm{s}]$ & 0.25 & 0.25 & 0.31 & 0.31 & 0.38 & 0.38 \\
$\Delta \mathrm{H}_{\text {pump }}[\mathrm{m}]$ & 1.01 & 1.03 & 1.35 & 1.36 & 1.78 & 1.80 \\
$\Delta \mathrm{H}_{\text {filter }}[\mathrm{m}]$ & 0.39 & 0.40 & 0.52 & 0.54 & 0.72 & 0.74 \\
$\mathrm{~J}[\mathrm{~m} / \mathrm{km}]$ & 59.38 & 58.48 & 93.25 & 92.78 & 140.73 & 133.52 \\
$\mathrm{Y}_{1}[\mathrm{~m}]$ & 1.50 & 1.50 & 1.50 & 1.50 & 1.50 & 1.50 \\
$\mathrm{Y}_{2}[\mathrm{~m}]$ & 1.48 & 1.48 & 1.47 & 1.47 & 1.46 & 1.46 \\
$\mathrm{Y}_{3}[\mathrm{~m}]$ & 2.49 & 2.51 & 2.82 & 2.83 & 3.24 & 3.26 \\
$\mathrm{Y}_{4}[\mathrm{~m}]$ & 2.44 & 2.47 & 2.75 & 2.76 & 3.13 & 3.15 \\
$\mathrm{Y}_{5}[\mathrm{~m}]$ & 2.05 & 2.07 & 2.22 & 2.22 & 2.39 & 2.41 \\
$\mathrm{Y}_{6}[\mathrm{~m}]$ & 1.98 & 1.99 & 2.10 & 2.11 & 2.22 & 2.24 \\
$\mathrm{Y}_{7}[\mathrm{~m}]$ & 1.96 & 1.93 & 2.05 & 2.01 & 2.17 & 2.10 \\
$\mathrm{Y}_{8}[\mathrm{~m}]$ & 1.84 & 1.81 & 1.86 & 1.82 & 1.88 & 1.83 \\
\hline
\end{tabular}

Table 3: Experimental vs numerical results in the case of $40 \mathrm{~g}\left(35 \mathrm{~g} \mathrm{~W}_{\mathrm{r}, \mathrm{s}}\right)$ of sand added for clogging

\begin{tabular}{lcccccc}
\hline & \multicolumn{2}{c}{ Minimum Velocity } & \multicolumn{2}{c}{ Intermediate Velocity } & \multicolumn{2}{c}{ Maximum Velocity } \\
\hline & Experim. & Numerical. & Experim. & Numerical. & Experim. & Numerical. \\
$\mathrm{Q}[\mathrm{l} / \mathrm{s}]$ & 0.26 & 0.26 & 0.33 & 0.33 & 0.39 & 0.39 \\
$\Delta \mathrm{H}_{\text {pump }}[\mathrm{m}]$ & 0.98 & 1.00 & 1.40 & 1.40 & 1.67 & 1.69 \\
$\Delta \mathrm{H}_{\text {filter }}[\mathrm{m}]$ & 0.32 & 0.33 & 0.49 & 0.50 & 0.60 & 0.62 \\
$\mathrm{~J}[\mathrm{~m} / \mathrm{km}]$ & 65.14 & 66.26 & 109.48 & 107.48 & 146.82 & 138.28 \\
$\mathrm{Y}_{1}[\mathrm{~m}]$ & 1.50 & 1.50 & 1.50 & 1.50 & 1.50 & 1.50 \\
$\mathrm{Y}_{2}[\mathrm{~m}]$ & 1.48 & 1.48 & 1.47 & 1.47 & 1.46 & 1.46 \\
$\mathrm{Y}_{3}[\mathrm{~m}]$ & 2.47 & 2.48 & 2.87 & 2.87 & 3.14 & 3.15 \\
$\mathrm{Y}_{4}[\mathrm{~m}]$ & 2.42 & 2.43 & 2.79 & 2.79 & 3.02 & 3.05 \\
$\mathrm{Y}_{5}[\mathrm{~m}]$ & 2.09 & 2.10 & 2.29 & 2.29 & 2.41 & 2.43 \\
$\mathrm{Y}_{6}[\mathrm{~m}]$ & 2.01 & 2.02 & 2.15 & 2.16 & 2.23 & 2.26 \\
$\mathrm{Y}_{7}[\mathrm{~m}]$ & 1.98 & 1.95 & 2.08 & 2.04 & 2.18 & 2.11 \\
$\mathrm{Y}_{8}[\mathrm{~m}]$ & 1.85 & 1.82 & 1.86 & 1.83 & 1.88 & 1.83 \\
\hline
\end{tabular}

Table 4: Experimental vs numerical results in the case of $50 \mathrm{~g}\left(48 \mathrm{~g} \mathrm{~W}_{\mathrm{r}, \mathrm{s}}\right)$ of sand added for clogging 
Experimental and Numerical Analysis of the Hydraulic Performance ...G. Viccione and S. Evangelista

\begin{tabular}{lcccccc}
\hline & \multicolumn{2}{c}{ Minimum Velocity } & \multicolumn{2}{c}{ Intermediate Velocity } & \multicolumn{2}{c}{ Maximum Velocity } \\
\hline & Experim. & Numerical. & Experim. & Numerical. & Experim. & Numerical. \\
$\mathrm{Q}[\mathrm{l} / \mathrm{s}]$ & 0.26 & 0.26 & 0.32 & 0.32 & 0.39 & 0.39 \\
$\Delta \mathrm{H}_{\text {pump }}[\mathrm{m}]$ & 0.95 & 0.97 & 1.34 & 1.31 & 1.65 & 1.67 \\
$\Delta \mathrm{H}_{\text {filter }}[\mathrm{m}]$ & 0.30 & 0.30 & 0.42 & 0.42 & 0.58 & 0.59 \\
$\mathrm{~J}[\mathrm{~m} / \mathrm{km}]$ & 67.24 & 65.92 & 98.37 & 103.27 & 146.83 & 137.58 \\
$\mathrm{Y}_{1}[\mathrm{~m}]$ & 1.50 & 1.50 & 1.50 & 1.50 & 1.50 & 1.50 \\
$\mathrm{Y}_{2}[\mathrm{~m}]$ & 1.48 & 1.48 & 1.47 & 1.47 & 1.46 & 1.46 \\
$\mathrm{Y}_{3}[\mathrm{~m}]$ & 2.43 & 2.45 & 2.81 & 2.78 & 3.10 & 3.13 \\
$\mathrm{Y}_{4}[\mathrm{~m}]$ & 2.38 & 2.40 & 2.74 & 2.70 & 2.99 & 3.02 \\
$\mathrm{Y}_{5}[\mathrm{~m}]$ & 2.08 & 2.10 & 2.31 & 2.28 & 2.40 & 2.43 \\
$\mathrm{Y}_{6}[\mathrm{~m}]$ & 2.00 & 2.02 & 2.18 & 2.15 & 2.22 & 2.26 \\
$\mathrm{Y}_{7}[\mathrm{~m}]$ & 1.97 & 1.95 & 2.04 & 2.04 & 2.16 & 2.11 \\
$\mathrm{Y}_{8}[\mathrm{~m}]$ & 1.83 & 1.82 & 1.84 & 1.82 & 1.86 & 1.83 \\
\hline
\end{tabular}

Table 5: Experimental vs numerical results in the case of $60 \mathrm{~g}\left(46 \mathrm{~g} \mathrm{~W}_{\mathrm{r}, \mathrm{s}}\right)$ of sand added for clogging

\begin{tabular}{lcccccc}
\hline & \multicolumn{2}{c}{ Minimum Velocity } & \multicolumn{2}{c}{ Intermediate Velocity } & \multicolumn{2}{c}{ Maximum Velocity } \\
\hline & Experim. & Numerical. & Experim. & Numerical. & Experim. & Numerical. \\
$\mathrm{Q}[\mathrm{l} / \mathrm{s}]$ & 0.25 & 0.25 & 0.31 & 0.31 & 0.37 & 0.37 \\
$\Delta \mathrm{H}_{\text {pump }}[\mathrm{m}]$ & 1.05 & 1.06 & 1.33 & 1.35 & 1.75 & 1.77 \\
$\Delta \mathrm{H}_{\text {filter }}[\mathrm{m}]$ & 0.41 & 0.41 & 0.52 & 0.54 & 0.72 & 0.74 \\
$\mathrm{~J}[\mathrm{~m} / \mathrm{km}]$ & 63.49 & 62.85 & 92.37 & 90.78 & 134.62 & 128.65 \\
$\mathrm{Y}_{1}[\mathrm{~m}]$ & 1.50 & 1.50 & 1.50 & 1.50 & 1.50 & 1.50 \\
$\mathrm{Y}_{2}[\mathrm{~m}]$ & 1.48 & 1.48 & 1.47 & 1.47 & 1.46 & 1.46 \\
$\mathrm{Y}_{3}[\mathrm{~m}]$ & 2.54 & 2.55 & 2.81 & 2.82 & 3.21 & 3.23 \\
$\mathrm{Y}_{4}[\mathrm{~m}]$ & 2.49 & 2.50 & 2.73 & 2.75 & 3.11 & 3.13 \\
$\mathrm{Y}_{5}[\mathrm{~m}]$ & 2.07 & 2.09 & 2.20 & 2.21 & 2.37 & 2.39 \\
$\mathrm{Y}_{6}[\mathrm{~m}]$ & 1.99 & 2.01 & 2.09 & 2.10 & 2.21 & 2.23 \\
$\mathrm{Y}_{7}[\mathrm{~m}]$ & 1.96 & 1.94 & 2.03 & 2.01 & 2.14 & 2.09 \\
$\mathrm{Y}_{8}[\mathrm{~m}]$ & 1.83 & 1.81 & 1.84 & 1.82 & 1.86 & 1.83 \\
\hline
\end{tabular}

Table 6: Experimental vs numerical results in the case of $70 \mathrm{~g}\left(51 \mathrm{~g} \mathrm{~W}_{\mathrm{r}, \mathrm{s}}\right)$ of sand added for clogging

\begin{tabular}{lcccccc}
\hline & \multicolumn{2}{c}{ Minimum Velocity } & \multicolumn{2}{c}{ Intermediate Velocity } & \multicolumn{2}{c}{ Maximum Velocity } \\
\hline & Experim. & Numerical. & Experim. & Numerical. & Experim. & Numerical. \\
$\mathrm{Q}[\mathrm{l} / \mathrm{s}]$ & 0.24 & 0.24 & 0.32 & 0.32 & 0.38 & 0.38 \\
$\Delta \mathrm{H}_{\text {pump }}[\mathrm{m}]$ & 1.02 & 1.03 & 1.40 & 1.43 & 1.79 & 1.82 \\
$\Delta \mathrm{H}_{\text {filter }}[\mathrm{m}]$ & 0.40 & 0.40 & 0.57 & 0.58 & 0.77 & 0.78 \\
$\mathrm{~J}[\mathrm{~m} / \mathrm{km}]$ & 57.72 & 58.26 & 99.38 & 95.37 & 140.72 & 130.57 \\
$\mathrm{Y}_{1}[\mathrm{~m}]$ & 1.50 & 1.50 & 1.50 & 1.50 & 1.50 & 1.50 \\
$\mathrm{Y}_{2}[\mathrm{~m}]$ & 1.48 & 1.48 & 1.47 & 1.47 & 1.46 & 1.46 \\
$\mathrm{Y}_{3}[\mathrm{~m}]$ & 2.51 & 2.52 & 2.88 & 2.90 & 3.26 & 3.28 \\
$\mathrm{Y}_{4}[\mathrm{~m}]$ & 2.46 & 2.47 & 2.80 & 2.82 & 3.15 & 3.18 \\
$\mathrm{Y}_{5}[\mathrm{~m}]$ & 2.05 & 2.07 & 2.22 & 2.24 & 2.36 & 2.40 \\
$\mathrm{Y}_{6}[\mathrm{~m}]$ & 1.98 & 1.99 & 2.09 & 2.12 & 2.19 & 2.24 \\
$\mathrm{Y}_{7}[\mathrm{~m}]$ & 1.95 & 1.93 & 2.04 & 2.02 & 2.15 & 2.10 \\
$\mathrm{Y}_{8}[\mathrm{~m}]$ & 1.83 & 1.81 & 1.84 & 1.82 & 1.86 & 1.83 \\
\hline
\end{tabular}

Table 7: Experimental vs numerical results in the case of $80 \mathrm{~g}\left(62 \mathrm{~g} \mathrm{w}_{\mathrm{r}, \mathrm{s}}\right)$ of sand added for clogging

Finally, with reference to the minimum velocity condition, the piezometric profile, drawn after the experimental measurements and the calculations, is sketched in Figure 6. 


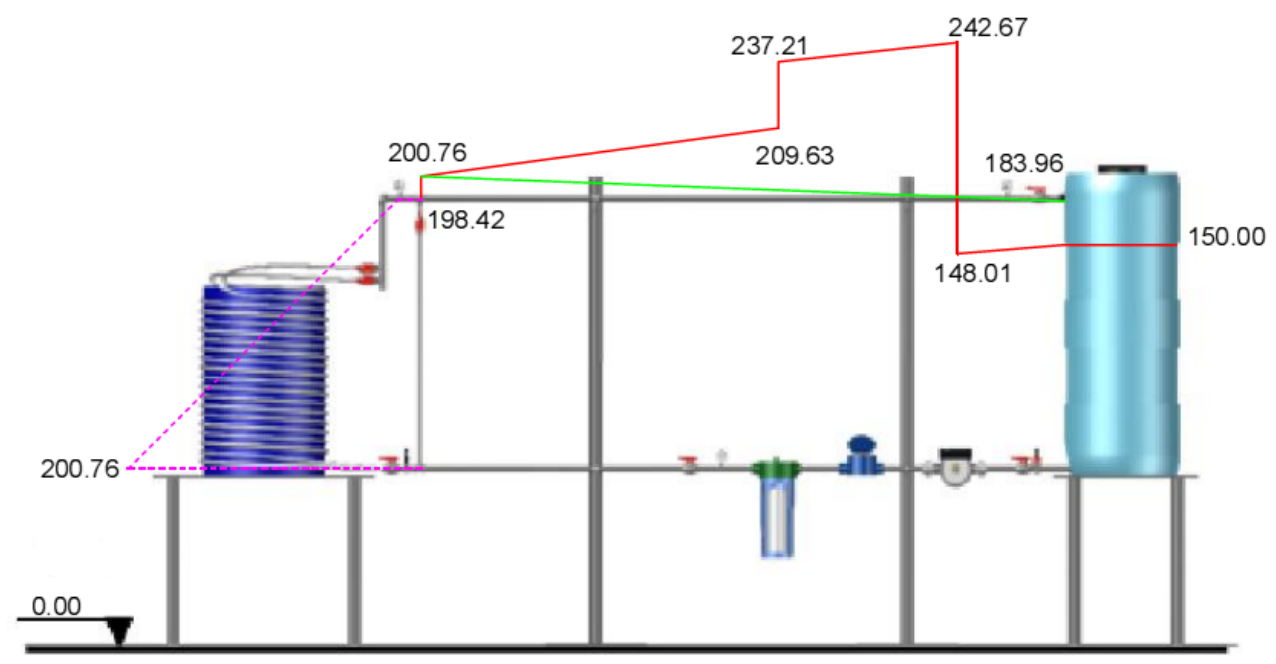

Figure 6: Piezometric lines on the galvanized steel pipe $\phi^{3 / 4}$ "

\section{Conclusions}

The hydraulic performance of commercial string-wound filtering cartridges for water treatment, was analyzed experimentally and numerically. Head losses were measured and computed with EPANET software, in terms of the amount of fine sand artificially applied over the external surface. After calibrating the roughness coefficient $\mathrm{C}$ of the Hazen - Williams formula, a good agreement was found.

\section{References}

Kanade, P., Koranne, M., \& Desai, T. (2017). Analysis of wound filter performance from DREF yarn spun at different suction pressure. Alex. Eng. J., 56, 115-121. doi:10.1016/j.aej.2016.09.012

Kanade, S., \& Bhattacharya, S. (2016). A Guide to Filtration with String Wound Cartridges, 1st Edition. Amsterdam, The Netherlands: Elsevier Ltd., ISBN: 9780128048474.

Logsdon, G. S. (2008). Water Filtration Practices (Including Slow Sand Filters and Precoat Filtration), 1st Edition. Denver, CO, US: American Water Works Association (AWWA), ISBN: 9781583215951.

Pawlowicz, M., Evans, J., Johnson, D., \& Brooks, R. (2006). A study of the efficacy of various home filtration substrates in the removal of microcystin-LR from drinking water. Journal of Water and Health, 4(1), 99-107. doi:10.2166/wh.2005.057

Rossman, L. (1999). Computer Models/EPANET. In L. Mays, Water Distribution Systems Handbook, Chapter 12 (pp. 12.1-12.23). New York, NY: McGraw-Hill companies, Inc.

Rossman, L. (2000). EPANET 2 Users Manual, EPA/600/R-00/057. Washington, DC, USA: United States Environmental Protection Agency public domain software.

Sutherland, K. (2008). Filters and Filtration Handbook, 5th Edition. Amsterdam, The Netherlands: Elsevier Ltd., ISBN: 9781856174640. 
Experimental and Numerical Analysis of the Hydraulic Performance ...G. Viccione and S. Evangelista

Tomaszewska, J., Jakubiak, S., Michalski, J., Pronk, W., Hug, S., \& Kurzydłowski, K. (2016). A polypropylene cartridge filter with hematite nanoparticles for solid particles retention and arsenic removal. Applied Surface Science, 366, 529-534. doi:10.1016/j.apsusc.2016.01.044

Viccione, G., \& Evangelista, S. (2017.a). Head losses induced by filtration cartridges in drinking water networks, paper ID: CEST2017_00576. 5th International Conference on Environmental Science and Technology (CEST2017) (pp. 1-5). Rhodes, Greece: Lekkas, D.F., ISBN: 9789607475534. Retrieved

from https://cest.gnest.org/sites/default/files/presentations_per_session.zip.

Viccione, G., \& Evangelista, S. (2017.b). A laboratory investigation of the hydraulic performance of string-wound filters, 1st Spring Euro-Mediterranian Conference for Environmental Integration (EMCEI2017) (pp. 111-112). Sousse, Tunisia: Kallel, A.; Ksibi, M.; Ben Dhia, H.; Khélifi, N. Springer: Berlin, Germany, ISBN: 9783319705477. doi:10.1007/978-3-31970548-4_38

Viccione, G., Evangelista, S., \& de Marinis, G. (2018.a). Experimental analysis of the hydraulic performance of wire-wound filter cartridges in domestic plants, Water, 10, 309, 1-15. doi:10.3390/w10030309

Viccione, G., Evangelista, S., \& de Marinis, G. (2018.b). Experimental Analysis of the Hydraulic Performance of Filtering Cartridges in Drinking Water Networks, 10(5), 629, 1-17. doi:10.3390/w10050629 